\title{
Partidos, políticos e suas bases: elementos da articulação política local-federal na geografia eleitoral de 2014
}

\section{Márcio Cunha Carlomagno}

\section{Resumo}

Este artigo analisa os padrões de votação (mensurados pelo índice $G$ de concentração de votos) obtidos por 5743 candidatos ao cargo de deputado federal em 26 estados brasileiros nas eleições de 2014. Seguindo a tese de que existe uma articulação política entre os níveis local e nacional, nosso objetivo é identificar se aspectos das bases políticas locais de que partidos dispõem (mensuradas por vereadores, prefeitos e governador do mesmo partido), influenciam nas estratégias de como candidatos obtém seus votos. Para isso, combinamos dados das eleições 2014 e de 2012, a partir de quatro diferentes bancos fornecidos pelo TSE. No modelo de regressão geral, ter vereadores do partido é o elemento de ordem política que mais afeta a tendência à dispersão da votação por todo o estado - em oposição à sua concentração em um nicho específico. Contudo, olhando os detalhes das correlações, existem distinções importantes entre os partidos. Sobre os grandes partidos, o PT tende a ter os resultados mais dispersos e PMDB e PSDB os mais concentrados. Os efeitos de cada tipo de base local também são diferentes a depender do partido, indicando que estes são afetados diferentemente por um mesmo fator. Palavras-chave: geografia do voto; conexão eleitoral; partidos políticos; político profissional; eleições.

\begin{abstract}
This article examines the voting patterns (measured by the $G$ index for votes concentration) obtained by 5743 candidates for the position of federal congressman in 26 Brazilian states in 2014 elections. Following the thesis that there is a political connection between the local and national levels, our goal is to identify whether aspects of local bases that political parties have (measured by councilors, mayors and governor of the same party), influence the strategies of how candidates get their votes. To do this, we combine data from elections in 2014 and 20I2, from four different databases provided by Brazilian Electoral Court. In general regression model, councilors is the
\end{abstract}

\section{Sobre o autor}

Mestre em ciência política pela Universidade Federal do Paraná. Email: mccarlomagno@gmail.com 
political element that most affects the tendency to spread the vote across the state as opposed to its concentration in a specific niche, as in a informal district. However, looking at the details of the correlations, there are important distinctions between the parties. On the major ones, PT tends to have the most outlying results and PMDB and PSDB the most concentrated. The effects of each local base are also different depending on the party, indicating that they are affected differently by the same factor. Keywords: electoral geography; electoral connection; political parties; professional politician; elections.

Artigo recebido em 30 de janeiro de 2015; aceito para publicação em 10 de março de 2015 .

\section{I.Introdução}

Este artigo analisa os padrões de votação obtidos por $5743^{1}$ candidatos ao cargo de deputado federal em 26 estados brasileiros nas eleições de 2014, nisto incluso os 505 eleitos - já descontados os 125 candidatos e 8 eleitos do Distrito Federal, que não integra esta análise ${ }^{2}$, sob o prisma da concentração de votos no Brasil. O padrão de votação obtido pelo candidato - cujo índice discutiremos na segunda seção - é tomado como variável dependente, a ser explicada. Nosso objetivo é identificar se aspectos da dinâmica política, essencialmente as bases de que partidos dispõem, influenciam nos resultados eleitorais.

A tese central que seguimos é o argumento de Avelino, Biderman \& Barone (2012,p. 988) sobre a "habilidade inesperada dos partidos de organizar seus esforços eleitorais não somente entre as eleições de um mesmo nível (nacional, estadual ou municipal), como também para eleições entre diferentes níveis, o que sugere capacidade de articulação entre os níveis de organização partidária.” Isto significa:

1 Outros 310 candidatos contabilizavam zero votos, na base de dados, devido ao fato de suas candidaturas terem sido impugnadas, e, por isto, foram excluídos desta análise. A versão do banco de dados utilizada é a de 28 de janeiro de 2015.

2 No caso do Distrito Federal, todos os votos são contabilizados como uma única cidade, Brasília, o que impossibilita a análise da distribuição geográfica do voto. Uma alternativa, para quem queira analisar o DF em específico, seria manter as 21 zonas eleitorais como um simulacro dos municípios. Optamos, contudo, como faz Silva (2014), por desconsiderar esta unidade federativa na presente pesquisa. 
se os partidos são organizados, teriam uma capacidade de articulação de suas bases locais (vereadores, prefeitos e governadores) para que estas trabalhassem em prol de candidatos em eleições de outros níveis, no caso em análise, para deputado federal.

Para verificar isto, combinamos nesta pesquisa dados das eleições 2014 e de 2012, utilizando quatro diferentes bancos de dados fornecidos pelo TSE. Analisaremos os recursos de articulação política em dois ambitos, que tocam tanto à estrutura partidária, quanto aos políticos profissionais. Se o argumento de Avelino, Biderman \& Barone de que ter uma base local é um diferencial nas eleições ${ }^{3}$ é verdadeiro para os partidos políticos, temos razões encontradas na literatura para crer que a afirmativa é especialmente verdadeira também para uma categoria profissional específica: os políticos. Isto se deve à sua capacidade potencial de articular apoios com outros políticos de demais níveis, uma vez já ter, em tese, estabelecido estes laços previamente.

A partir disto, apresentamos três hipóteses explicativas dos padrões de votação, cuja veracidade iremos testar.

Hipótese 1: É possível identificar distinções partidárias no tocante aos padrões de votação. Diversos estudos já mostraram que os partidos políticos brasileiros têm distintas capilaridades (BRAGA \& PIMENTEL JR, 2013). Historicamente, o PMDB tem sido o grande partido municipalista no Brasil, embora também o PT tenha amplas bases locais. Acreditamos que este suporte municipal influencia no comportamento dos candidatos ao buscar e obter seus votos, se ao longo de todo estado ou somente em um nicho eleitoral específico. Esta questão relata diretamente à discussão acerca de sua penetração no eleitorado brasileiro. Acreditamos que os grandes partidos nacionais, PT e PMDB, especialmente, além do PSDB, por sua projeção nacional, tendem a ter maior adesão nos municípios e, consequentemente, apresentarão um padrão mais disperso na geografia do voto.

3 Vale ressaltar que diferentemente de Pereira \& Rennó (2001) ou Codato, Cervi \& Perissinotto (2013) não tratamos, nesta análise, sobre as chances de eleger-se ou não, mas os caminhos para isto, seus pathways to power, no tocante às estratégias eleitorais adotadas de onde buscar os votos. 
Hipótese 2: A categoria profissional "político" implica em uma tendência a um padrão mais disperso de votação obtida. Silva (2014) apresenta os dados que, em São Paulo, políticos que se recandidatam obtêm votações mais dispersas do que a média geral. Cervi (2009) também argumenta que políticos profissionais e comunicadores $\&$ líderes religiosos tendem a ter votação mais dispersa. Por já mobilizar recursos próprios do campo - que concerne à nossa hipótese seguinte - acreditamos que o politico profissional, seja eleito ou não eleito, tende a apresentar valores de dispersão superiores aos não políticos.

Hipótese 3: Candidatos e partidos com maior apoio político local tendem a ter voto mais disperso. Esta é uma hipótese que se relaciona diretamente às duas primeiras e será testada de modo conjunto. Três variáveis serão utilizadas para mensurar as bases locais.

a) Pertencer ao partido do governador do estado. $\mathrm{O}$ argumento lógico é que o governador tem o controle de uma série de mecanismos institucionais de repasses de verbas aos municípios e, portanto, pode promover junto a estes suas políticas e de seu partido. Os candidatos do partido do governador tem mais argumentos junto aos eleitores para promover a ideia de que sua relação com o executivo estadual trouxe ou pode trazer recursos financeiros para o local. Isto pode funcionar, potencialmente, como um incentivo institucional à dispersão do voto, Pereira \& Rennó (2001) já demonstraram, para o caso de 1998, que ter o governador do estado influencia na dispersão dos votos dos candidatos daquele partido.

b) número de prefeitos do partido no estado, pelo mesmo motivo que será argumentado no item seguinte.

c) número de vereadores do partido no estado. Os políticos locais (prefeitos e vereadores) são o elo político mais próximo ao cidadão. Em uma campanha em que estes não necessitam buscar seus próprios votos, como a de deputado federal, podem potencialmente trabalhar por outros candidatos, de seu partido ou de sua articulação. Uma importante distinção neste ponto é que, enquanto Avelino, Biderman \& Barone (2012), assim como também Pereira \& Rennó (2001), levam em conta os votos dados ao partido para mensurar as transferências de votos que aquele partido tem, nós consideramos apenas a presença dos eleitos locais, justamente para verificar se a presença em um cargo municipal influencia nos votos para a eleição de deputados federais. Tanto o número de prefeitos quanto o de vereadores 
serão ponderados pelo total presente no estado, a fim de possibilitar a comparação entre todos estados brasileiros.

$\mathrm{Na}$ última parte da análise incluímos no modelo os gastos de campanha, para que possamos estabelecer um parâmetro de comparação com demais pesquisas da longa literatura que aponta a importância deste elemento (BOLOGNESI \& CERVI, 2011; SPECK, 2014; SPECK \& MANCUSO, 2013; CODATO, CERVI, PERISSINOTTO, 2013), verificando o quão significativo são os dados que serão apresentados aqui à luz de demais análises. Acreditamos que os gastos de campanha terão um efeito para todos partidos e segmentos, de forma indistinta. Não é, contudo, nosso objeto central.

$\mathrm{O}$ artigo se divide da maneira seguinte. Na primeira seção realizamos uma breve revisão teórica e metodológica da temática e apresentamos o modelo de análise aplicado. A seção seguinte é destinada à análise dos dados empíricos e divide-se em três partes principais. Nas duas primeiras apresentamos o fenômeno de forma mais introdutória, relacionando-o aos partidos políticos e aos políticos profissionais, verificando especialmente as diferenças de médias. $\mathrm{Na}$ terceira etapa, apresentamos um modelo de regressão e os impactos isolados, tanto para partidos quanto para políticos, usando testes de correlação de Pearson. Ao longo de todo artigo apresentaremos os resultados divididos tanto para os eleitos, quanto para os não eleitos, a fim de verificar as eventuais distinções entre estes dois grupos. A última seção é destinada às conclusões e à reflexão sobre as implicações dos achados para a compreensão das dinâmicas da política brasileira, sobretudo na relação entre os âmbitos local e federal em tempos eleitorais.

\section{Discussão teórica e metodológica}

onde candidatos e partidos buscam seus votos? Um dos aspectos possíveis pra responder a questão diz respeito à dimensão geográfica e os distintos padrões que nosso sistema eleitoral propicia. Ames (1995) argumentava que, no Brasil, existem essencialmente dois padrões de votação pelo qual os deputados se elegem: com votação geograficamente concentrada ou distribuída. A votação concentrada refere-se a parlamentares que obtém seus votos em um nicho eleitoral específico (como se fosse um voto distrital), ao passo que parlamentares com votação distribuída obtêm seus votos ao longo 
de todo o estado, não estando, portanto, sua eleição vinculada a apenas um distrito eleitoral. Ames, hoje já muito contestado tanto quanto a suas conclusões quanto aos seus métodos pra mensurar concentração, argumentava que o Brasil funcionaria como uma espécie de simulacro de um sistema distrital - distritos informais, em sua expressão - de votação, com a grande maioria dos deputados elegendo-se de forma regionalizada.

Contudo, tanto Avelino, Biderman \& Silva (2011) quanto Silva (2014) analisam a dimensão geográfica e demonstram que, além do tamanho e a magnitude do distrito servirem como um incentivo à concentração ou dispersão, na série histórica de 1994 a 2010, a tendência tem sido à desconcentração dos padrões de votação no Brasil.

Desde Ames, muito já se produziu e a relação entre este padrão de votação e o comportamento parlamentar se tornou um dos fortes temas de pesquisa na ciência política brasileira. Diversos estudos (FIGUEIREDO \& LIMONGI, 2002; RICCI \& LEMOS, 2004; MESQUITA et al, 2014) se propõem a analisar a relação entre votação obtida e a proposição de emendas parlamentares que destinem recursos aos municípios. De um modo geral, estes estudos encontram uma consonância entre padrão de votação e comportamento no parlamento. Isto é, deputados que se elegem por voto concentrado tendem a ter comportamento mais regionalista, do tipo pork barrel (paroquial), visando beneficiar suas bases eleitorais, ao passo que parlamentares eleitos por votação mais dispersa tendem a ter comportamento legislativo mais universalista, voltado a bandeiras temáticas (CARVALHO, 2009; CARVALHO, CORRÊA, GHIGGINO, 2010).

A linha geral de argumentação é lastreada no pressuposto da teoria racional (DOWNS, 2013) de que, autointeressados, o primeiro objetivo dos políticos é chegar ou manter-se no poder. Seu comportamento no legislativo ou no governo será, pois, voltado a este interesse primeiro - para Downs, os eventuais benefícios públicos são uma função incidental dos atores competindo por seus interesses pessoais. A ideia também é alicerçada no pressuposto do incentivo institucional ao cultivo de determinado tipo de base social e obtenção do voto (CARREY \& SHUGART, 1995). Uma vez que se elegem por vias distintas, o comportamento destes indivíduos tende a ser, supostamente, distinto. 
A maioria dos estudos da linha de conexão eleitoral, contudo, analisa os aspectos geográficos como uma variável explicativa do comportamento do parlamentar, mas poucos, como o de Avelino, Biderman \& Barone (2012) ou Pereira \& Rennó (2001), levam em conta aspectos da natureza do jogo político para explicar as diferenças nestes padrões de votação, como faremos neste artigo. Nós seguiremos aqui um objeto próximo ao analisado pelo recém-citado trio. Tendo o município como unidade de análise, estes autores compararam os votos dados a prefeitos na eleição municipal anterior, com a eleição estadual de 2010. Argumentam que eleger um prefeito aumentaria os votos para o seu partido nas eleições proporcionais seguintes. Este será parte de nosso modelo de análise.

Um problema dos estudos na linha da geografia do voto é que, assim como é comum também a outras linhas de pesquisa da ciência política, não há consenso sobre qual a melhor forma para mensurar a concentração de votos. Na literatura existem muitas propostas diferentes de modelos metodológicos, como resumem Avelino, Biderman e Silva (2011). Há pelo menos sete modelos distintos e razoavelmente aceitos pela literatura (AMES, 1995; SAMUELS, 2002; PEREIRA E RENNÓ, 2001, 2009; SOARES \& TERRON, 2008; CERVI, 2009; MESQUITA et al, 2014), entre outros. Optamos, aqui, pela utilização do Índice G de Florence, do modelo proposto por Avelino, Biderman e Silva (2011).

Uma das grandes vantagens deste modelo, ao contrário de alguns demais, é que os votos são ponderados pela distribuição esperada. Em outras palavras, um candidato pode obter $50 \%$ de seus votos em uma única cidade/região, mas se esta cidade/região concentrar 50\% do eleitorado, sua votação não é concentrada, mas distribuída de forma normal, ao passo que, o mesmo candidato pode obter $10 \%$ de seus votos em uma cidade/ região que concentra apenas $2 \%$ do eleitorado, o que, aí sim, indicaria a concentração de votos. Este fator não é levado em conta por modelos anteriores. Outra vantagem da utilização deste modelo, razoavelmente bem utilizado, é poder dialogar com a literatura e comparar os resultados.

O procedimento que realizamos para o cálculo dos dados neste estudo pode ser sumarizado pela equação abaixo:

$$
G=\sum_{M}\left(\frac{V d m}{V d}-\frac{V m}{V t}\right)^{2}
$$

Fonte:Avelino, Biderman e Silva (20II) 
Onde: $\mathrm{Vdm}=$ votos do deputado no município; $\mathrm{Vd}=$ total de votos do deputado; $\mathrm{Vm}=$ Total de votos dados a algum deputado naquele município, naquele ano; $\mathrm{Vt}=$ total de votos dados a algum deputado no estado, naquele ano.

A fonte de todos os dados utilizados nesta pesquisa são os bancos fornecidos pelo TSE. Combinamos os três diferentes bancos de dados do TSE para 2014 e utilizamos elementos de todos para compor a análise; do arquivo sobre prestação de contas, as informações sobre gastos de campanha; do arquivo sobre os candidatos, sua profissão e do arquivo sobre resultados eleitorais, seu padrão de votação - além da utilização do banco sobre os resultados eleitorais de 2012, de onde extraímos as informações sobre prefeitos e vereadores eleitos.

Sobre os gastos de campanha, cabe ressaltar que utilizamos os valores reais, a partir do arquivo de prestações de contas final à justiça eleitoral. Alguns estudos usam apenas o valor de gasto previsto declarado à Justiça Eleitoral no momento do registro da candidatura, mas como este é apenas o teto estimado ${ }^{4}$, e não o real dispendido, isso pode gerar eventuais erros.

Para a variável vereador, foi utilizado o percentual de vereadores do partido no estado, pelo total de vereadores no estado. A mesma lógica vale para os prefeitos. Os gastos de campanha também foram ponderados (por candidato, claro), pelo total gasto pelos candidatos àquele cargo, no mesmo estado, para que pudéssemos ter dados objetivamente comparáveis entre estados muito distintos.

Para a construção da variável "partido do governador" foi considerado o governador eleito que exerceu o mandato, ainda que este, como por vezes é usual ocorrer, tenha deixado o mandato em março daquele ano eleitoral para concorrer a outros cargos. Para os casos em que o governador trocou de partido, foi considerado o partido a que o governador pertencia durante as eleições de 2014 - ou ao sair do cargo, para aqueles que o deixaram na situação recém-descrita.

Para a categorização de profissões, que utilizamos brevemente na próxima seção, antes de dicotomizar político e não-político, utilizamos o mesmo modelo empregado na longa discussão da literatura

4 Ocorre que o candidato não pode ultrapassar o valor total declarado como previsto, de forma que muitos candidatos declaram uma previsão muito acima do que realmente é esperado ou executado, a fim de evitar sanções no decorrer da campanha. 
específica (COSTA, CODATO, MASSIMO, 2013; RODRIGUES, 2002; 2006; CORADINI, 2012; ROJAS \& CARLOMAGNO, 2014), obtendo, essencialmente, oito categorias profissionais: político profissional, comunicadores e líderes religiosos, empresários, professores, profissões liberais e intelectuais, servidor público, trabalhadores e outros. Depois disto, a transformamos em uma binária que distingue apenas os políticos profissionais e todos os demais..$^{5}$ Chegamos a realizar um teste com uma categoria alternativa, separando os autodeclarados "deputados" e "outros políticos", a fim de verificar se eventualmente os incumbentes no cargo teriam alguma vantagem competitiva mesmo sobre os demais tipos de políticos - sobretudo por causa dos resultados pouco expressivos que serão apresentados na tabela 5. Entretando, não ocorreram diferenças significativas entre os dois tipos de político, ao que preferimos manter a categoria mais geral de politico profissional.

Para a agregação dos partidos por ideologia, também seguimos as classificações consagradas pela literatura específica (ZUCCO JR, 2009; MARENCO DOS SANTOS, 2001; BRAGA \& NICOLÁS, 2008; COSTA, BOLOGNESI, CODATO, 2015). Embora nossas hipóteses de investigação não versem diretamente sobre as distinções ideológicas no comportamento eleitoral dos partidos (algum pesquisador da área poderá tirar as conclusões que deseje) este tipo de agregação é bem aceito no campo. Nosso objetivo nesta agregação é mais pragmático: tornar a análise mais palpável e compreensível, visto que tabelas e gráficos que incluíssem os 32 partidos brasileiros inevitavelmente tenderiam ao enfado do leitor. Para fins desta análise, são denominados pequenos partidos de esquerda (sem eleitos): PCB; PCO; PPL e PSTU. Pequenos partidos de esquerda (com eleitos): PCdoB e PSOL. Grandes partidos de esquerda (ou centro-esquerda): PDT e PSB. Partidos de centro: PPS e PV. Grandes partidos de direita: DEM, PSD, PROS, PP, PR, PSC e SD. E finalmente pequeno partidos de direita: PEN, PHS, PMN, PRB, PRP, PRTB, PSDC, PSL, PTdoB, PTB, PTC e PTN.

5 Realizamos um teste com uma categoria alternativa, separando os auto-declarados “deputados" e "outros políticos", a fim de verificar se eventualmente os incumbentes no cargo teriam alguma vantagem competitiva mesmo sobre os demais tipos de políticos. Entretando, não ocorreram diferenças significativas, ao que preferimos manter a categoria mais geral de politico profissional. 
Além de deixar os maiores partidos brasileiros (PT, PMDB e PSDB) desagregados, afinal, é importante entender seu comportamento de forma direta, dividimos os chamados pequenos partidos de esquerda entre os com e os sem eleitos. Esta divisão não é necessária para estudos sobre características da elite política, mas quando tratamos de padrões de resultados eleitorais, sim. Como no caso dos pequenos partidos de direita apenas um deles não tinha eleitos, $o$ agregamos a este grupo mesmo assim (sem tal divisão), dada a baixa possibilidade de alteração dos padrões do grupo.

\section{Análise}

\section{I Partidos}

Explicado o tratamento realizado nos dados na seção anterior, passaremos à análise. Como já dito, nosso corpus é composto por 5743 candidatos a deputado federal que concorreram nas eleições 2014, nisto incluso os 505 eleitos (descontados os deputados do Distrito Federal).

Para começar, vamos às médias entre eleitos e não eleitos 6 . Silva (2014) já havia demonstrado que a tendência entre os eleitos claramente é a dispersão dos votos. Também para o caso de 2014. Enquanto entre os eleitos, a média é de ,0926, entre os não eleitos a média é de ,2395. Estes valores estão rigorosamente no mesmo patamar com o que a literatura demonstra, com os eleitos um pouco abaixo da média de 2010, o que corrobora a tese de Silva (2014) do processo de crescente tendência à desconcentração dos votos no Brasil. Este padrão, contudo, não é único para todos os partidos políticos brasileiros. É o que iremos verificar a seguir.

6 Testamos a divisão da categoria "não eleitos" em duas, dos com menos e mais do que um X de votos (foi testado para os limites de 100 e 500 votos), a fim de evitar possíveis distorções causadas por candidatos não competitivos que obtém um número irrisório de votos. Contudo, as diferenças dos dois grupos de não eleitos não apresentaram nenhum sentido analítico relevante, sendo muito próximos na maior parte dos testes realizados, ao que mantivemos o grupo como um só, da mesma forma que já o faz a literatura de referência. 
Tabela I - Médias do índice de concentração de votos para partidos, por situação eleitoral

\begin{tabular}{|c|c|c|c|c|c|c|}
\hline \multirow[t]{2}{*}{ Partido } & \multicolumn{3}{|c|}{$\begin{array}{c}\text { Média } \\
\text { Situação }\end{array}$} & \multicolumn{3}{|c|}{$\begin{array}{c}\text { Desvio padrão } \\
\text { Situação }\end{array}$} \\
\hline & Eleito & Não eleito & Total & Eleito & Não eleito & Total \\
\hline DEM & ,0587 &, 2150 & , 1923 & ,06299 & , 19860 & , 19309 \\
\hline$P C$ do $B$ & , 1084 & , I848 & , 1742 & , 15198 & 19324 & 18900, \\
\hline PCB & & 1794, & 1794 & & I7524, & I7524, \\
\hline $\mathrm{PCO}$ & & , 1270 & , 1270 & & , 10556 & , 10556 \\
\hline PDT & I067| & 2089 & , 1983 & ,09728 & 20887 & 20598, \\
\hline PEN & ,0559, &, 2413 & 2395 & I & , 18460 & , 18460 \\
\hline PHS & ,0508 & ,2922 & ,2866 & ,05846 & ,20675 & 20770 \\
\hline PMDB & ,0857 & ,2117 & , 1866 & 10969 &, 21612 & 20566 \\
\hline PMN & ,0462 & ,2738 & ,2688 & ,03994 & ,21169 & ,21205 \\
\hline PP & ,0859 & , 1988 & , 1715 &, 13612 & 20928 & , 19970 \\
\hline PPL & & ,2042 & ,2042 & & , 17105 & , 17105 \\
\hline PPS & , I460 & 2405, & 2320 & 12667, & 19483 & , 19124 \\
\hline PR & , 1095 & & 2390 & 19923, & 24510, & 24483, \\
\hline PRB & , 1078 & ,2580 & ,2438 & , 15933 & ,22894 & ,22731 \\
\hline PROS & ,0928 & ,2693 & ,2497 & ,06997 & ,24466 & ,23820 \\
\hline PRP & ,3105 & ,2401 & 1 & ,21369 & ,2204I & ,21999 \\
\hline PRTB & ,255I & ,2406 & ,2407 & & , 18959 & | 18908 \\
\hline PSB & ,0996 & ,2480 & ,2335 & , II &, 21600 & ,21297 \\
\hline PSC & ,0272 & , 1945 & , 1802 & ,02100 & , 19137 & , I8896 \\
\hline PSD & ,0843 & ,2000 & , 1737 & ,09737 & , 19255 & , 18184 \\
\hline PSDB & , II 75 & , 1846 & , 1716 & , 12765 &, 18419 & , I7649 \\
\hline PSDC & ,0926 & ,2913 & ,2890 &, 10168 & , 19109 &, 19133 \\
\hline PSL &, 0121 & ,2482 & 2467, & & 17079, & , 17126 \\
\hline PSOL &, 1250 & ,2592 & ,2574 & , I2093 & | & | I8878 \\
\hline PSTU & & , 1907 & , 1907 & & , I5954 & , I5954 \\
\hline PT & ,0902 & , I775 & , 1603 & , 10092 & , I8480 & | \\
\hline PT do B & 0909 & ,2877 & ,2867 & & , 21041 & ,21035 \\
\hline PTB & ,0942 & ,2437 & I & ,09983 & ,22878 & ,22310 \\
\hline PTC & , 1029 & ,2762 & ,2741 & ,09864 & ,21049 & ,21021 \\
\hline PTN & , I708 & ,2881 & ,2835 &, 11219 & ,20524 & 20335 \\
\hline PV & ,0822 & ,2574 &, 2519 & 09090 & , 19188 & , 19189 \\
\hline SD &, 0414 & ,2670 & 2441 & ,05074 & 22696 & ,22620 \\
\hline Total &, 0926 & ,2395 & ,2265 & , II & 20585 & ,20403 \\
\hline
\end{tabular}

Fonte: o autor, a partir dos dados do TSE

Percebemos que, salvo o PRP e o PRTB, em todos os partidos com eleitos, estes tem um padrão razoavelmente mais disperso do que os não eleitos, seguindo a tendência geral. O PSDB é um dos partidos com menor diferença das duas médias, tal como o PT. Mas, 
enquanto no PSDB a distância se deve ao nível elevado da média dos eleitos, no PT os não eleitos apresentam uma das menores médias desta categoria. Isto é, os dois partidos apresentam distâncias semelhantes entre os dois grupos, por motivos diferentes. Enquanto no PSDB os eleitos tendem a ser mais concentrados, no PT mesmo os não eleitos tendem a ser mais dispersos. Entre os partidos relevantes, o PT é o que apresenta, no total de todos candidatos, a menor concentração.

A seguir, testaremos a hipótese de que pertencer ao partido do governador exerce alguma influência nos resultados que o partido obtém. O recurso que iremos utilizar para apresentar estes dados é o gráfico do tipo diagrama de caixa (boxplot). Uma das vantagens deste tipo de gráfico, além de reunir uma série de informações conjuntamente, é retirar automaticamente da análise os valores discrepantes (outliers), que são apresentados na imagem em forma de círculos ou estrelas. Estes valores podem afetar as médias gerais, portanto, este gráfico nos dá dados mais precisos.

Percebemos, com o gráfico recém-apresentado, que os valores de concentração para o PT são ainda menores do que os expostos nas médias. Detendo a análise somente para a classe dos eleitos, podemos notar que o comportamento esperado para o grupo dos que tem suporte do governador se concretiza para o PT, assim como para o PSB, PROS e o PSD: tendo o executivo do estado, seus candidatos tendem a ser mais desconcentrados. Contudo, o efeito é inverso para o PMDB e o PSDB. Isto é, quando estes dois partidos estão no governo do estado, seus candidatos tendem a ser mais concentrados - curiosamente, o efeito esperado da dispersão ocorre para o PSDB entre os não eleitos.

Podemos argumentar algumas hipóteses explicativas para o inesperado resultado de PSDB e PMDB (a variação é maior neste segundo). A nossa hipótese era que o partido no governo estadual tem mecanismos institucionais de transferência de recursos, o que favorece a penetração dos partidários desta agremiação nos municípios - e resulta na maior dispersão de sua votação. O que pode explicar PSDB e PMDB apresentarem resultados significativos, mas em sentido oposto, reside em que os benefícios do governo do estado podem ser distribuídos de muitas maneiras diferentes, tanto em políticas públicas mais amplas, quanto em ações paroquialistas. Isto pode ser uma indicação do tipo de política pública que cada um destes partidos adota, quando no governo - que potencialmente gera efeitos distintos no eleitorado. 
Gráfico I -Valores da concentração de votos por partido, controlado por candidato ser do partido do governador

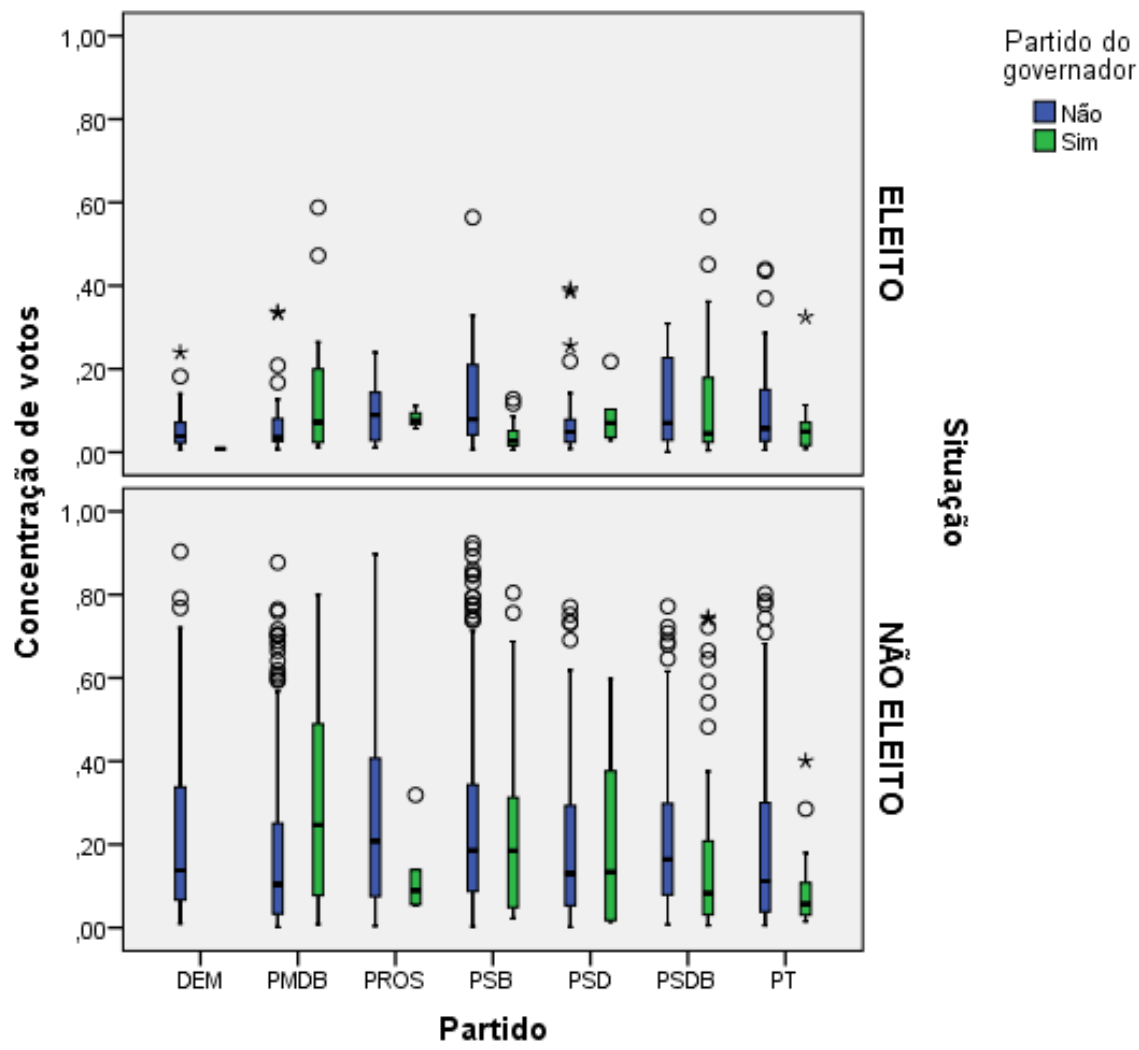

Fonte: o autor, a partir dos dados do TSE

Embora tanto PT quanto PMDB e PSDB tenham governadores tanto no nordeste, quanto no sul e sudeste, sendo improvável que este resultado seja efeito de uma variável interveniente tal como tipo de concentração em dado estado, esta é uma explicação possível, que precisará ser testada ${ }^{7}$. Se este comportamento eleitoral por parte do cidadão é resultado do tipo de política adotada por cada partido, de avaliação do governo ou qualquer outra hipótese que se queira

7 Aqui, não é nosso objetivo adentrar na temática dos estado ou regiões. Testamos, contudo, estes dados. O PT apresenta compotamento mais disperso independentemente do estado. Em São Paulo, por exemplo, estado onde as médias são muito concentradas, o PT apresenta níveis impressionantes de dispersão. 
formular, apenas investigações futuras poderão responder. De qualquer forma, a importância do governo do estado se confirmou: os efeitos existem, o que muda entre os partidos é apenas a direção do vetor. Retornaremos à questão partidária adiante.

\subsection{0 politico profissional}

O fenômeno que iremos perseguir nesta seção é a relação entre o político profissional e as bases políticas que ele dispõe para serem, potencialmente, mobilizadas em sua campanha. Vamos começar por identificar a diferença, de saída, que políticos profissionais tem perante outras ocupações.

Tabela 2 - Índice de concentração de votos e categoria profissional

\begin{tabular}{|c|c|c|c|c|c|c|}
\hline \multirow[t]{2}{*}{ Profissão } & \multicolumn{3}{|c|}{$\begin{array}{c}\text { Média } \\
\text { Situação }\end{array}$} & \multicolumn{3}{|c|}{$\begin{array}{l}\text { Desvio padrão } \\
\text { Situação }\end{array}$} \\
\hline & Eleito & Não eleito & Total & Eleito & Não eleito & Total \\
\hline $\begin{array}{l}\text { Político } \\
\text { profissional }\end{array}$ & ,0815 & ,3447 & ,2330 & , 10336 & , 27048 & ,25207 \\
\hline $\begin{array}{l}\text { Comunicadores e } \\
\text { líderes religiosos }\end{array}$ & ,0828 & ,2726 & , 2584 & ,06962 & ,23367 & ,23093 \\
\hline Empresários & , 1166 & ,2453 & ,2367 & , I4583 & , 21176 & ,21042 \\
\hline Outros & ,0399 & ,2094 & ,2055 &, 04614 & , 18637 & , 18609 \\
\hline Professores & , 1485 & , 2559 & ,2527 & , 14362 &, 19525 & , 19464 \\
\hline $\begin{array}{l}\text { Profissões liberais } \\
\text { e intelectuais }\end{array}$ & , 1036 & ,2361 & ,2231 & , I2463 & ,20569 & ,20305 \\
\hline Servidor público & , $|20|$ & ,2193 & , 2169 &, 10139 & , 18432 & , 18336 \\
\hline Trabalhadores & , I70I & ,2391 & ,2382 & ,30520 & , 19367 & , 19537 \\
\hline Total & ,0926 & ,2395 & ,2265 & , 11940 & ,20588 & 20406, \\
\hline
\end{tabular}

Fonte: 0 autor, a partir dos dados do TSE

Os valores seguem as tendências já relatadas pela literatura (SILVA, 2014; CERVI, 2009). Políticos profissionais e comunicadores \& líderes religiosos com tendência a ter votação mais dispersa do que as demais categorias profissionais, embora, neste caso, a distância não seja assim tão abismal. A nota de estranhamento fica por conta do comportamento apresentado pela categoria "outros"

8 A categoria “outros" está originalmente no branco de dados do TSE. Apesar de existirem outras 600 categorias para ocupação profissional, historicamente apresenta um valor muito alto. 
cuja explicação permanecerá remanescente, visto não ser o tema deste estudo.

A partir deste momento, para deixar a análise mais dinâmica e objetiva, iremos utilizar a agregação dos partidos por ideologia, que já explicamos em seção anterior, e a categoria profissional apenas aquela que nos interessa nesta pesquisa, isto é, ser político profissional em uma variável binária, sim ou não.

Gráfico 2 - Concentraçao de votos por partido, controlado por ser ou não político profissional

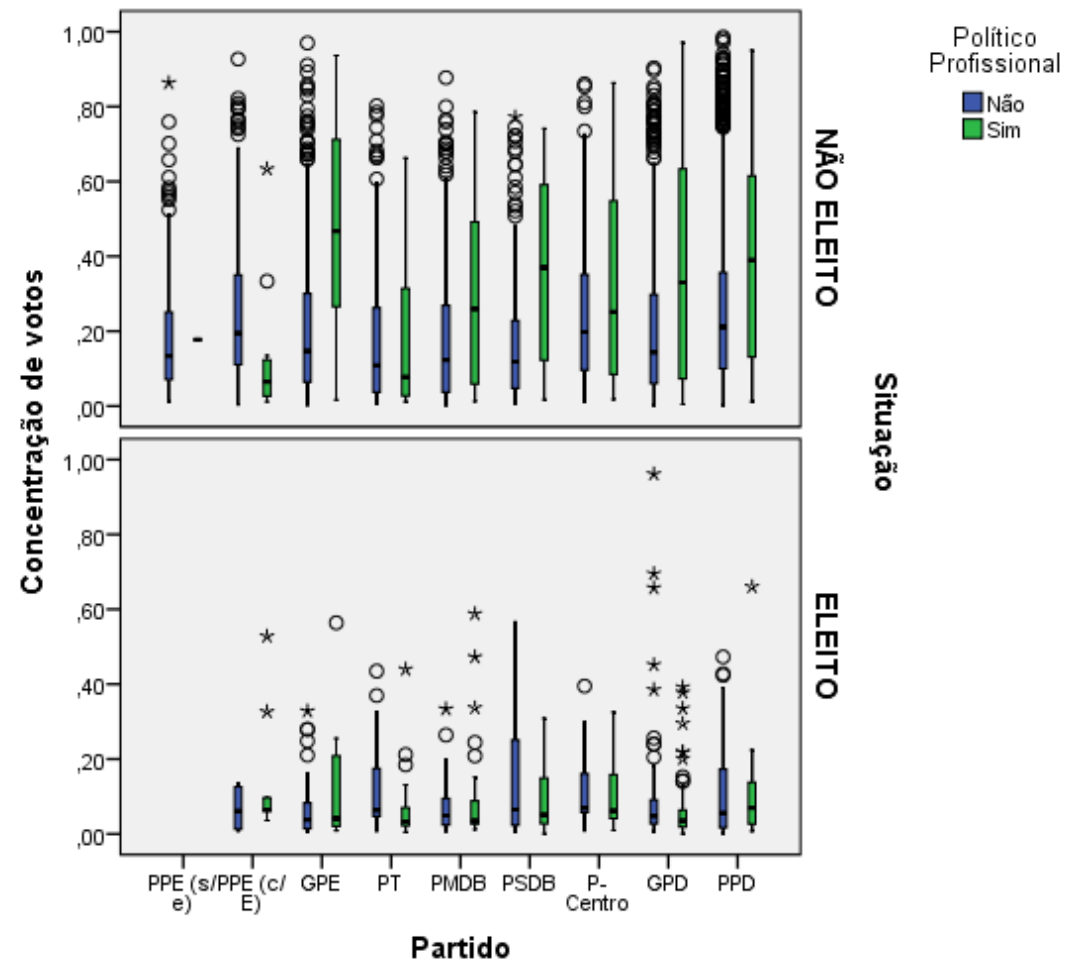

Fonte: o autor, a partir dos dados do TSE 
A pergunta preliminar aqui é se ser político profissional em partidos diferentes, implica em distintos efeitos no que tange os outcomes eleitorais?

Um comportamento inesperado é que, para os não eleitos, ser político profissional implica em ser mais concentrado eleitoralmente do que as demais categorias profissionais. Isto vale, com distâncias diferentes, para quase todos os partidos - exceção feita aos pequenos partidos de esquerda. Isto é explicado pelo alto número de "vereadores" que se candidataram naquele pleito. No que toca aos eleitos, existem distinções pontuais, mas o padrão geral se mantém: políticos profissionais tendem a ser mais dispersos eleitoralmente do que os profissionais de demais áreas. A exceção, agora, é para os políticos profissionais nos grandes partidos de esquerda (PDT e PSB) e nos partidos de centro (PPS e PV). Para estes, os políticos eleitos tem padrão de votação mais concentrado do que os demais eleitos pelo mesmo partido.

Importante ainda notar também que, para o caso do PSDB, embora seus políticos sejam mais dispersos do que os demais eleitos do partido, o teto do limite superior é praticamente o mais alto entre os políticos eleitos. Entre os não políticos, é o maior limite superior com larga vantagem. Isto já apresenta a tendência que iremos demonstrar adiante, com dados adicionais, à um padrão de concentração deste partido.

Agora, vamos às variáveis de ordem política. A seguir, apresentamos dois gráficos, com a relação dos políticos profissionais com o suporte obtido por prefeitos e vereadores. Vamos deter este momento da análise somente sobre os eleitos. Para o caso do apoio dos vereadores, percebemos que ter até $5 \%$ ou acima de $15 \%$ do total de vereadores do estado em seu partido não produz diferenças significativas, em termos gerais (na próxima seção destrincharemos este efeito por partido). Contudo, o intervalo entre $5 \%$ e $10 \%$ produz um resultado visível sobre a concentração do limite superior dos analisados. Percebemos que a mediana praticamente não se altera, ou seja, aqueles que já eram dispersos, continuam assim, sem grandes impactos; o efeito está naqueles acima de ,30 de concentração, que então são reduzidos para a casa dos ,20.

Um movimento quase idêntico acontece com a base de apoio dos prefeitos. Ter até $5 \%$ dos prefeitos do estado em seu partido não produz nenhuma diferença significativa entre políticos e não políticos. No intervalo entre $5 \%$ e $10 \%$, a distância cresce drasticamente. Os padrões são quase os mesmos, em termos gerais. Veremos, adiante, que existem algumas diferenças entre os dois tipos de base de apoio. 
Gráfico 3 - Concentraçao de votos por político profissional e base de vereadores

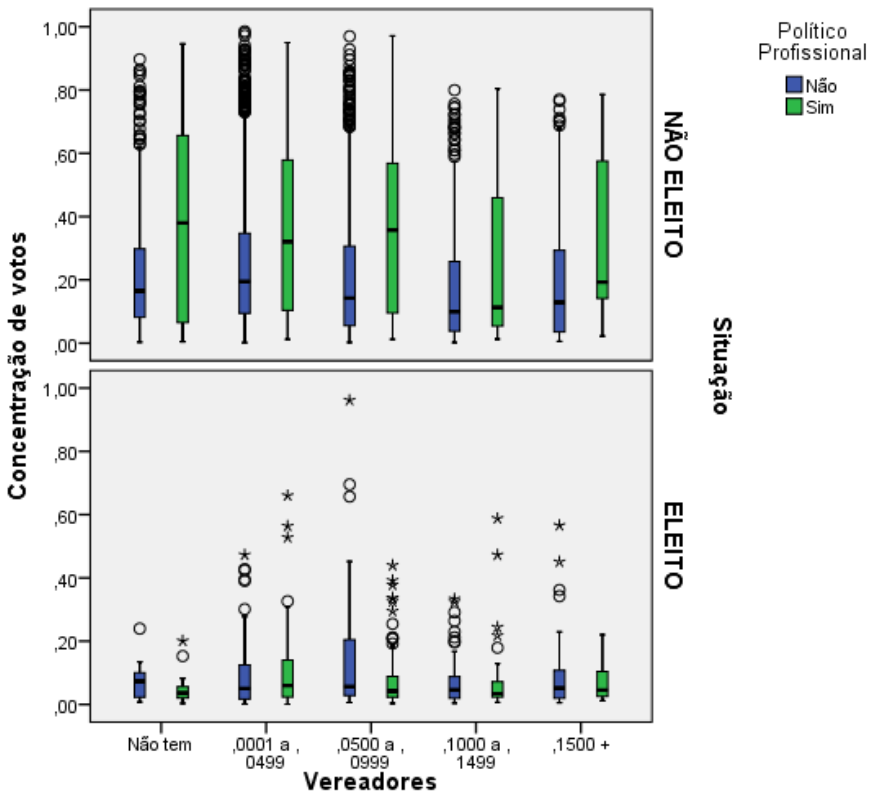

Gráfico 4-Concentraçao de votos por político profissional e base de prefeitos

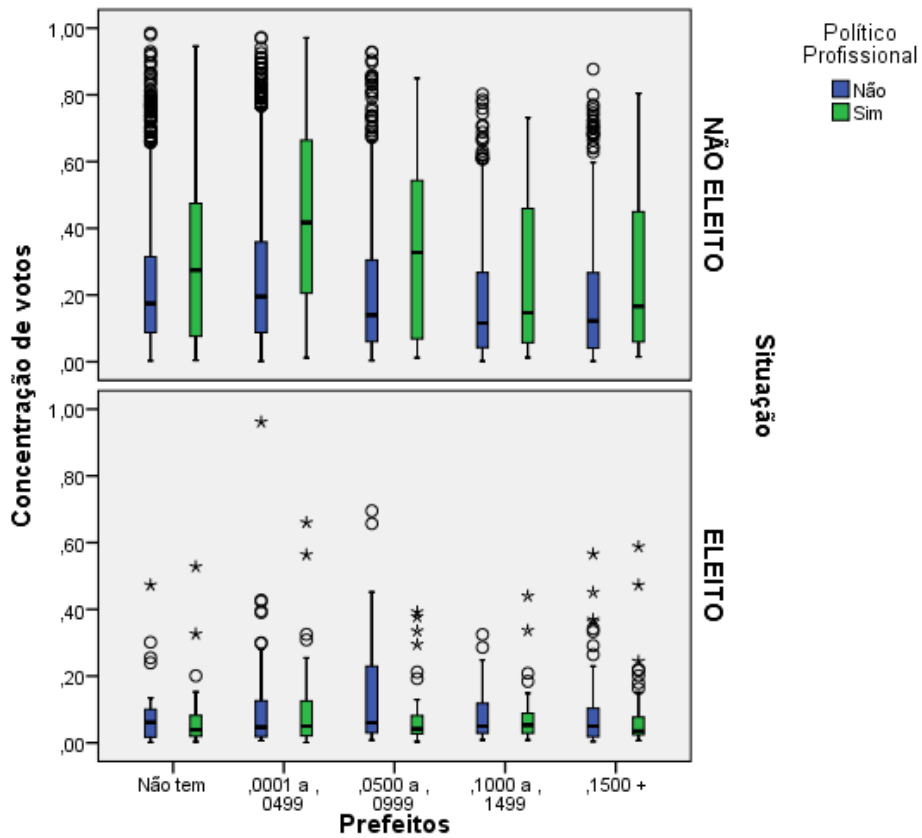

Fonte: o autor, a partir dos dados do TSE 
Acreditamos ser de grande valor olhar para estas mudanças no comportamento do objeto ao mudar condições ambientes. Se olhássemos apenas para os resultados gerais de político profissional, a tendência é que este tivesse uma votação mais dispersa, mas ao cotejarmos com outras variáveis notamos as gradações. Ser político profissional não implica em, obrigatoriamente, obter um padrão de votação distinto de outras categorias profissionais. Isto depende da presença de outras condições. Neste caso, para casos de candidatos com até $5 \%$ dos políticos de seu partido em cargos municipais (vereador e prefeito), ser político profissional ou não é indiferente para obter mais votos distribuídos por todo o estado. As condições mudam, quase que drasticamente, a partir deste patamar. Este parece ser uma evidência muito clara da articulação local que os partidos e políticos mobilizam para suas eleições de objetivo nacional.

\subsection{Outros testes}

Nas duas subseções anteriores apresentamos dados gerais acerca do fenômeno, utilizando suas médias, para identificá-lo. Agora, para encaminhar a conclusão desta análise, iremos proceder alguns testes mais robustos. Primeiramente, um modelo de regressão mais geral, para todas variáveis. Em seguida, utilizamos as correlações comparando os grupos para encontrar os detalhes provocados pela presença de ser um político profissional e de partido político. A partir daqui, passamos a considerar também os gastos de campanha, ponderados pelo total de cada estado. Seguem primeiramente os dados do modelo geral. Na regressão, o $\beta$ padronizado, juntamente com o sig., é o valor mais importante. Tanto este quanto o coeficiente de correlação variam potencialmente de zero (nenhuma correlação) a um (correlação perfeita), podendo este ser negativo ou positivo. $\mathrm{O}$ sig. indica a significância daquele elemento e a chance de erro. $\mathrm{O}$ ideal é em ,000, sendo até ,050 aceitável (indicaria uma possibilidade de erro em 5\%). Acima disto, os valores do coeficiente devem ser desconsiderados, pois não tem valor estatístico real. 
Tabela 3 - Correlação de pearson para concentração de votos

\begin{tabular}{lrrr}
\hline & \multicolumn{3}{c}{ Concentração de votos } \\
\cline { 2 - 4 } & $\begin{array}{r}\text { Correlação } \\
\text { de Pearson }\end{array}$ & $\begin{array}{c}\text { Sig. (2 } \\
\text { extremidades) }\end{array}$ & N \\
\hline Concentração de votos & I & & 5743 \\
Prefeitos do partido &,$- 105^{* *}$ &, 000 & 5743 \\
Vereadores do partido &,$- 122^{* *}$ &, 000 & 5743 \\
Gastos de campanha &,$- 212^{* *}$ &, 000 & 4731 \\
Governador &,$- 075^{* *}$ &, 000 & 5743 \\
Político profissional &, 011 &, 407 & 5743 \\
$* *$ A correlação é significativa no nível 0,01 (2 extremidades). & \\
\hline
\end{tabular}

Fonte: o autor, a partir dos dados do TSE

Tabela 4 - Regressão linear para concentração de votos

\begin{tabular}{lrrrrr}
\hline & \multicolumn{2}{c}{$\begin{array}{c}\text { Coeficientes não } \\
\text { padronizados }\end{array}$} & $\begin{array}{c}\text { Coeficientes } \\
\text { padronizados }\end{array}$ & t & Sig. \\
\cline { 2 - 3 } & B & $\begin{array}{c}\text { Erro } \\
\text { padrão }\end{array}$ & Beta & & \\
\hline Constante) &, 261 &, 004 & & 61,495 &, 000 \\
Vereadores &,- 688 &, 159 &,- 160 & $-4,321$ &, 000 \\
Prefeitos &, 340 &, 119 &, 119 & 2,869 &, 004 \\
Governador &,- 035 &, 017 &,- 039 & $-2,102$ &, 036 \\
Político Profissional &, 088 &, 010 &, 139 & 9,061 &, 000 \\
Gastos de campanha & $-1,756$ &, 205 &,- 142 & $-8,570$ &, 000 \\
Situação eleitoral &,- 131 &, 012 &,- 193 & $-11,191$ &, 000 \\
\hline
\end{tabular}

Fonte: $\mathrm{o}$ autor, a partir dos dados do TSE

Neste modelo geral, a primeira questão que chama especial atenção é que todos os fatores preditores são significativos. O mais forte deles, já sabíamos de antemão, situação eleitoral. Entre os elementos exclusivos de nosso modelo, vereadores e prefeitos aparecem igualmente significativos, mas em sentidos opostos. $\mathrm{Ou}$ seja, ter vereadores de seu partido ajuda a pulverizar o voto, ao passo que ter muitos prefeitos de seu partido ajuda a concentrar o voto nestes municípios. O valor positivo para político profissional está enviesado pela acentuada concentração destes quando não eleitos - já mostramos os dados na seção anterior e retomaremos a questão a seguir. Ao passo que a questão sobre gastos de campanha - a variável mais significativa após situação eleitoral - é mais uma contribuição à longa literatura sobre a importância do dinheiro nas eleições. Governador é o que menos importa neste 
modelo, mas ainda assim significativo. Isto pode ser um indício de que as relações na política brasileira - ou ao menos no período eleitoral - se deem diretamente entre o nível local e o federal, com uma menor participação ou importância do executivo estadual.

A seguir, iremos apresentar as correlações de Pearson encontradas para as variáveis explicativas, utilizando a ferramenta de comparação de grupos, a fim de verificar o impacto de ser político profissional e do partido político na relação entre estas variáveis e a concentração de votos. Como são muitos valores, especialmente nos dados sobre partidos, iremos assinalar os mais relevantes para a nossa análise, como é usual.

Tabela 5 - Correlação de pearson para concentraçao de votos, controlado para político profissional e situaçao eleitoral

\begin{tabular}{|c|c|c|c|c|c|c|c|}
\hline & \multirow{2}{*}{\multicolumn{2}{|c|}{$\begin{array}{c}\text { Eleitos } \\
\text { Político } \\
\text { Profissional }\end{array}$}} & \multirow{2}{*}{\multicolumn{2}{|c|}{$\begin{array}{l}\text { Não Eleitos } \\
\text { Político } \\
\text { Profissional }\end{array}$}} & \multirow{2}{*}{\multicolumn{2}{|c|}{$\begin{array}{c}\text { Geral } \\
\text { Político } \\
\text { Profissional }\end{array}$}} \\
\hline & & & & & & & \\
\hline & & Não & Sim & Não & Sim & Não & Sim \\
\hline \multirow{3}{*}{ 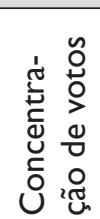 } & $\begin{array}{l}\text { Correlação de } \\
\text { Pearson }\end{array}$ & I & I & I & I & I & I \\
\hline & $\begin{array}{l}\text { Sig. (2 } \\
\text { extremidades) }\end{array}$ & & & & & & \\
\hline & $\mathrm{N}$ & 247 & 258 & 4888 & 350 & 5135 & 608 \\
\hline \multirow{3}{*}{ 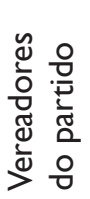 } & $\begin{array}{l}\text { Correlação de } \\
\text { Pearson }\end{array}$ &,- 043 &,- 098 &,$- 09 \mid * *$ &,$- \mid 115^{*}$ &,$-|1| 3 * *$ &,$- 199 * *$ \\
\hline & $\begin{array}{l}\text { Sig. (2 } \\
\text { extremidades) }\end{array}$ &, 505 &, 116 & 000 & ,031 & ,000 &, 000 \\
\hline & $\mathrm{N}$ & 247 & 258 & 4888 & 350 & 5135 & 608 \\
\hline \multirow{3}{*}{ 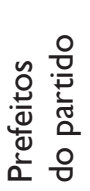 } & $\begin{array}{l}\text { Correlação de } \\
\text { Pearson }\end{array}$ &,- 017 &,- 035 &,$- 072 * *$ &,$- 126 *$ &,$- 095 * *$ &,$- 176 * *$ \\
\hline & $\begin{array}{l}\text { Sig. (2 } \\
\text { extremidades) }\end{array}$ & ,785 & ,579 & 000 &, 019 & , 000 &, 000 \\
\hline & $\mathrm{N}$ & 247 & 258 & 4888 & 350 & 5135 & 608 \\
\hline \multirow{3}{*}{ 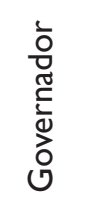 } & $\begin{array}{l}\text { Correlação de } \\
\text { Pearson }\end{array}$ & ,009 &,- 042 &, $060 * *$ & ,089 &, $075^{* *}$ & ,085* \\
\hline & $\begin{array}{l}\text { Sig. (2 } \\
\text { extremidades) }\end{array}$ & ,892 & ,502 & ,000 & ,097 & ,000 & 035 \\
\hline & $\mathrm{N}$ & 247 & 258 & 4888 & 350 & 5135 & 608 \\
\hline \multirow{3}{*}{ 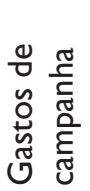 } & $\begin{array}{l}\text { Correlação de } \\
\text { Pearson }\end{array}$ &,$- 240 * *$ &,$- 182 * *$ &,$- 110 * *$ &,$- 452 * *$ &,$- 170 * *$ &,$- 385 * *$ \\
\hline & $\begin{array}{l}\text { Sig. (2 } \\
\text { extremidades) }\end{array}$ &, 000 & ,003 & ,000 & ,000 & , 000 &, 000 \\
\hline & $\mathrm{N}$ & 247 & 258 & 3885 & 341 & 4132 & 599 \\
\hline
\end{tabular}

**A correlação é significativa no nível 0,01 (2 extremidades).

* A correlação é significativa no nível 0,05 (2 extremidades).

Fonte: o autor, a partir dos dados do TSE 


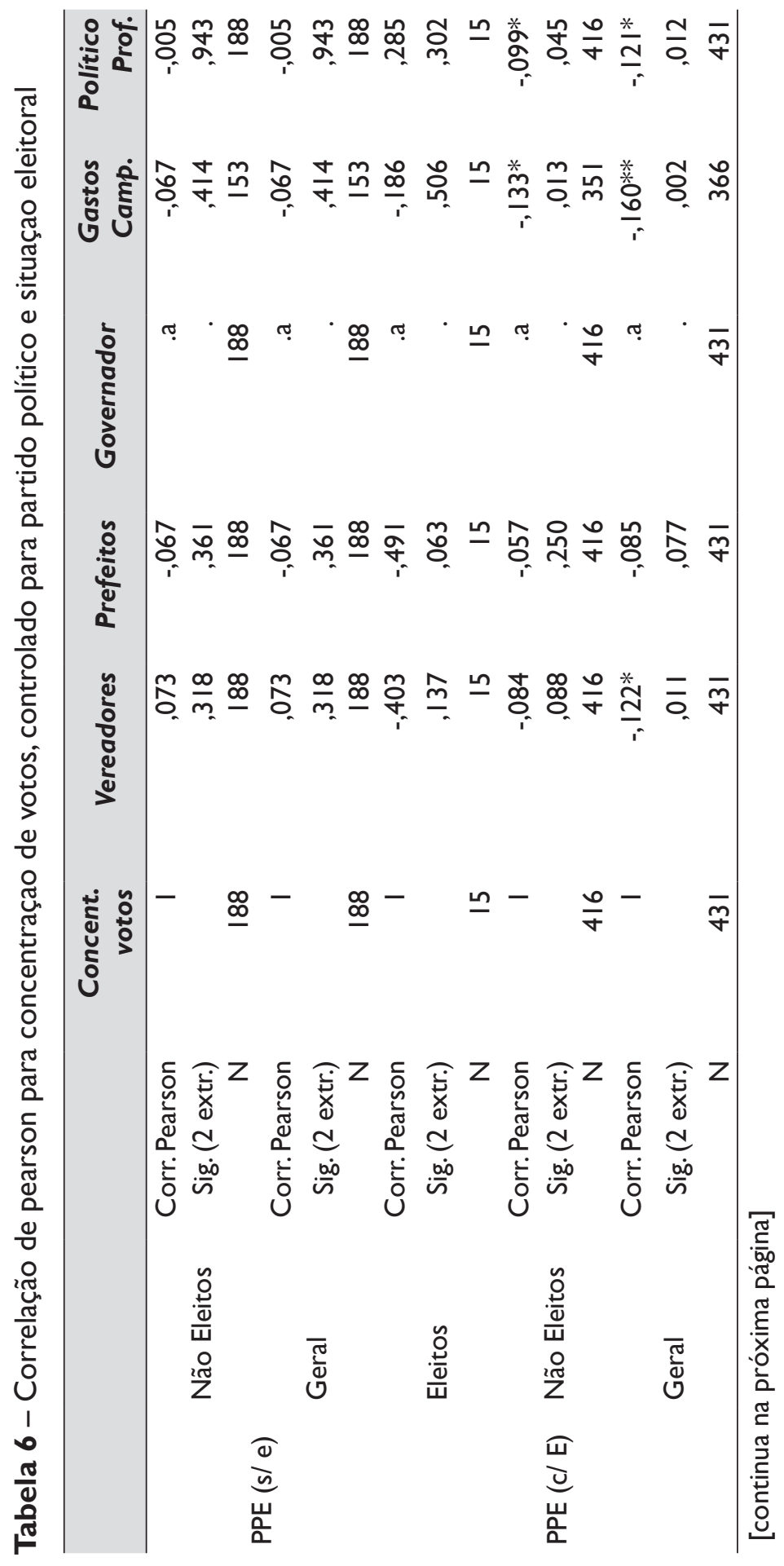




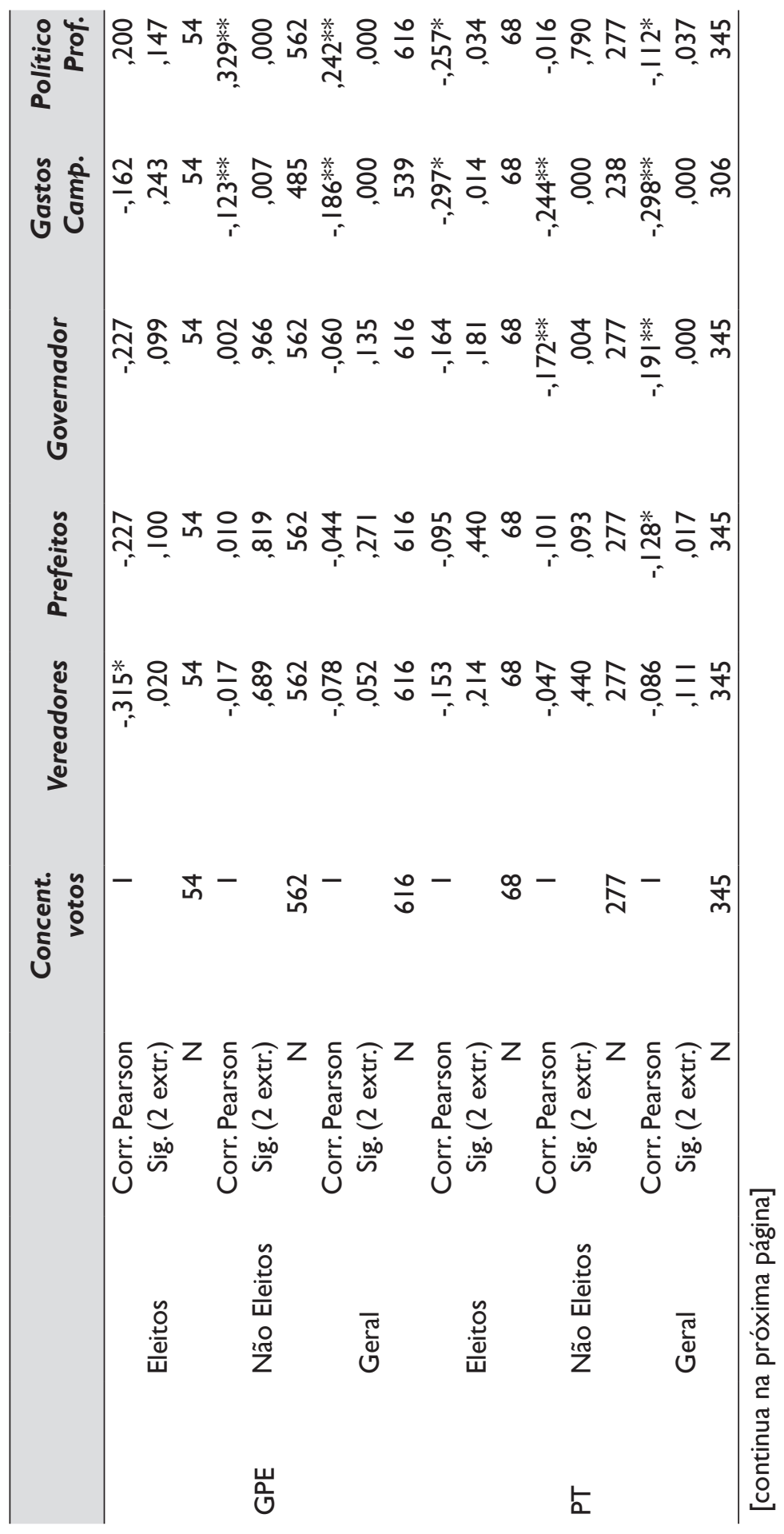




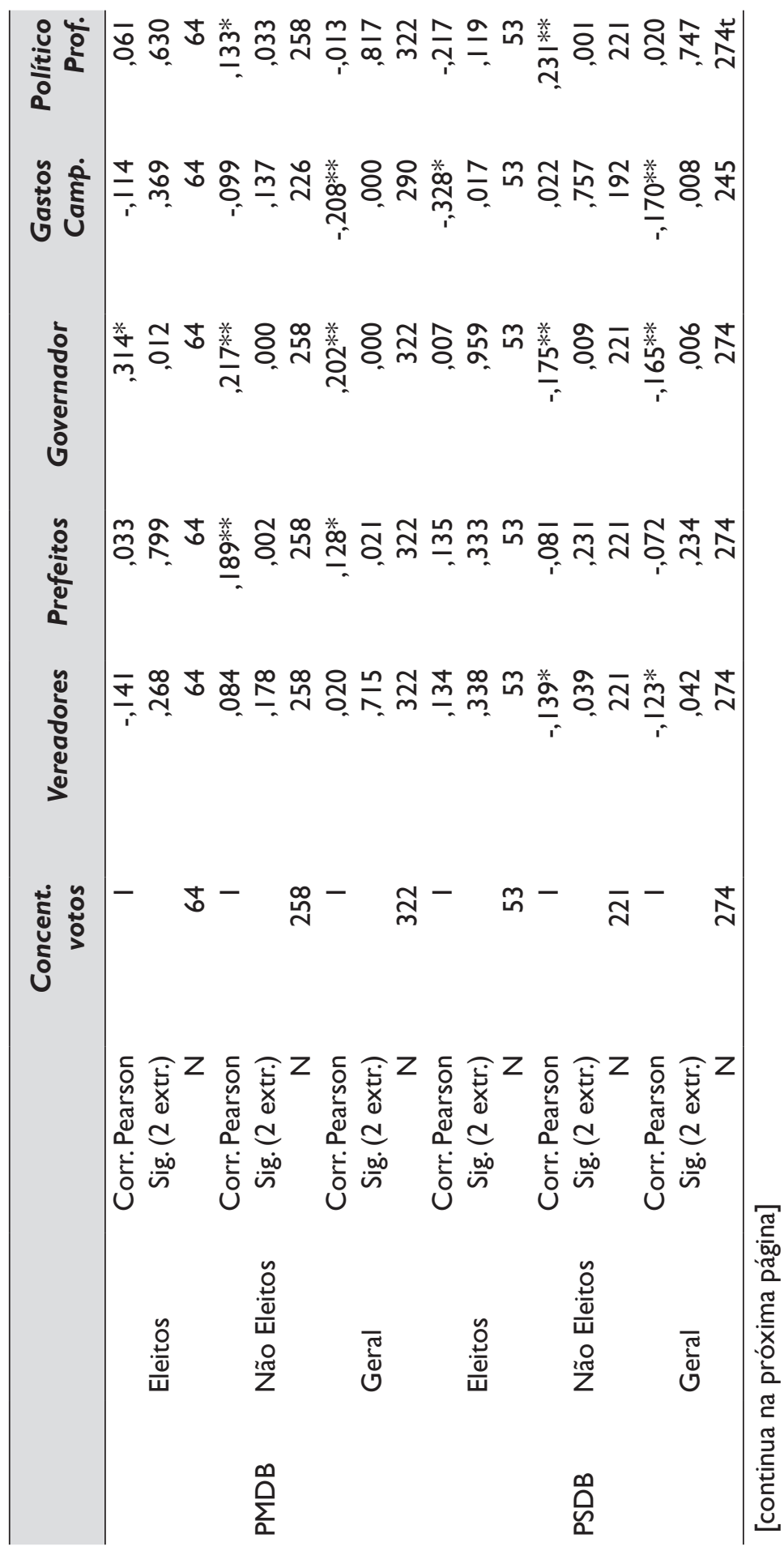




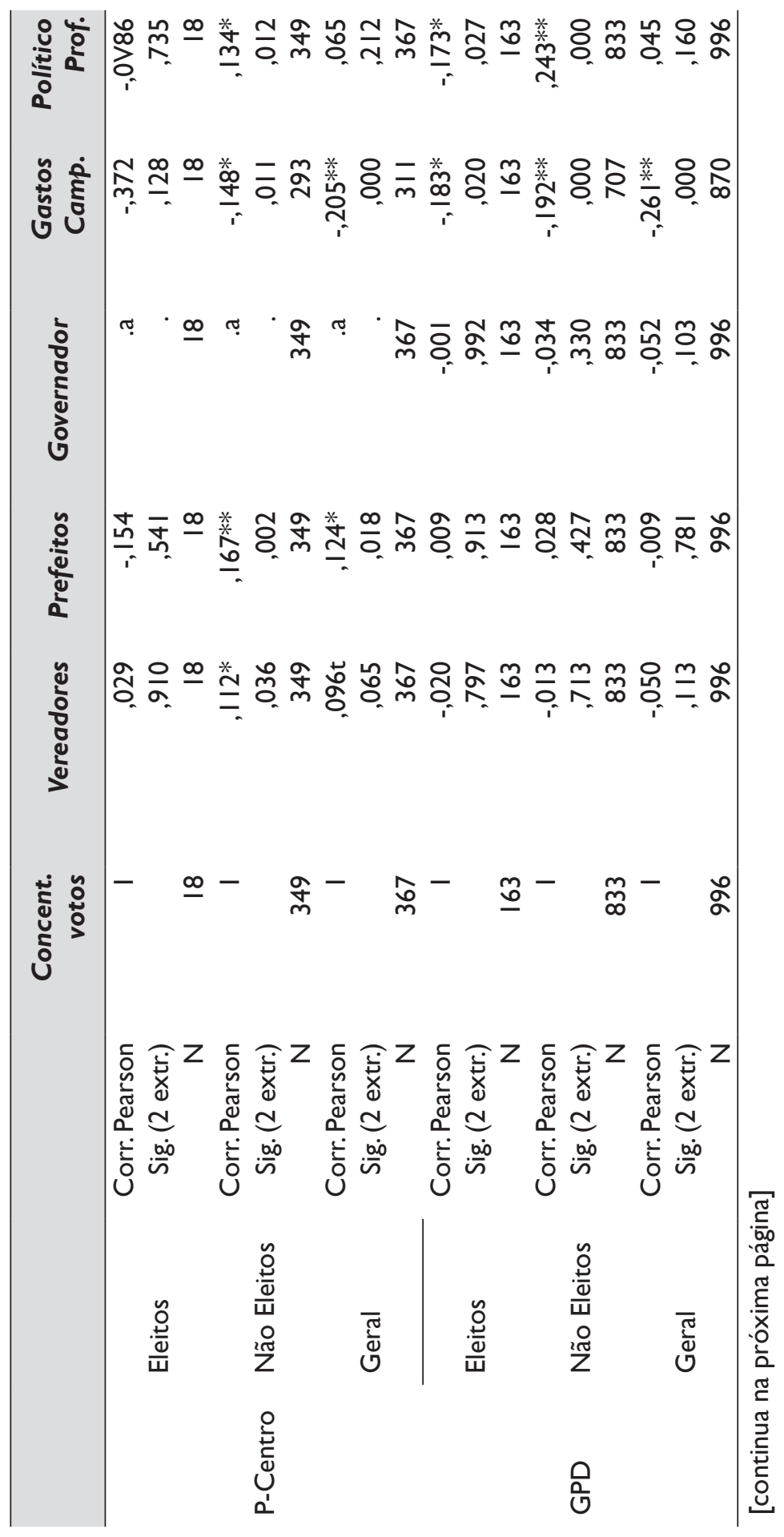




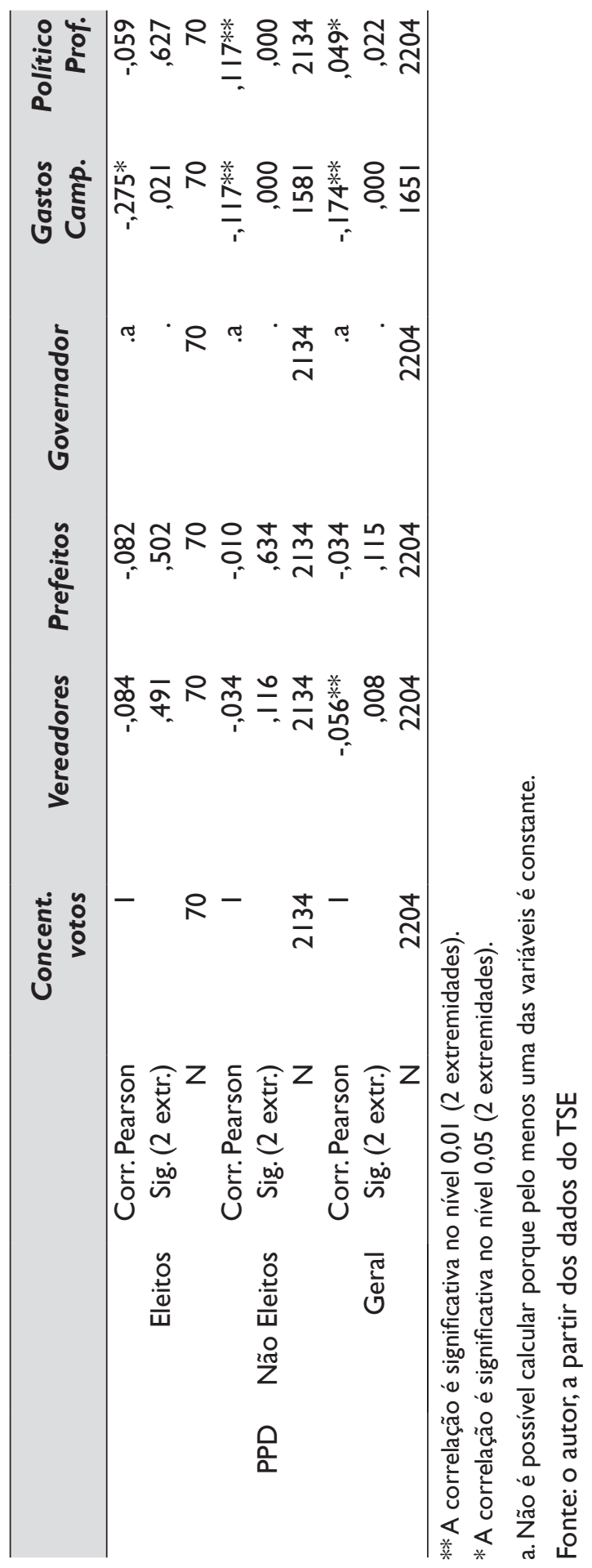


Sobre os políticos profissionais, nesta comparação de grupos, levando em conta os valores para o quadro geral (todos candidatos), todos os fatores crescem em significância quando passamos dos não políticos para os políticos, mas em valores distintos. A importância dos prefeitos quase dobra e a dos vereadores cresce uma distância de ,086, enquanto a do governador cresce apenas ,010. Este é um indicador de que o caminho de articulação política para campanhas eleitorais para deputado federal é via as relações municipais, seja com prefeitos ou vereadores. Neste cenário, para um político profissional concorrendo à deputado federal, vereadores são 2,3 vezes mais importantes para a dispersão de sua votação do que o governador do estado. Por outro lado, percebemos que os valores são significativos quando tratamos de todos os candidatos ou dos não eleitos. Para os eleitos, o mesmo não ocorre. Neste grupo, não há diferenças estatisticamente significativas em relação às bases políticas entre ser um político profissional ou não sê-lo. Significa dizer, entre os eleitos, ocorre um processo de normalização. Os maiores impactos em ser um político profissional e ter bases locais de apoio está entre aqueles não eleitos. Discutiremos as implicações disto nas considerações finais.

Já sobre os partidos políticos, os efeitos mais significativos da presença de vereadores são para os partidos de centro-esquerda (PDT e PSB) e para os pequenos partidos de esquerda, no sentido de ajudar na dispersão dos votos - além do PSDB, mas somente quando considerados tanto eleitos quanto não eleitos. Tanto sobre prefeitos quanto sobre governador do estado, há uma distinção muito interessante encontrada. Para ambos, tanto PT quanto PMDB foram significativos. E para ambos, em sentido oposto. No PT, ter prefeitos ou o governador tende a ajudar na dispersão dos votos; no PMDB, os dois elementos tendem a colaborar na concentração de votos.

Quanto às diferenças de ser político profissional em cada partido, as mais evidentes é que este fato leva a uma dispersão do voto quanto tratamos dos pequenos partidos de esquerda, do PT e dos grandes partidos de direita (somente para os eleitos). Já nos partidos de centro-esquerda, de centro e nos pequenos partidos de direita, os políticos profissionais destas agremiações tendem a concentrar seus votos em dados nichos. Não há nenhum efeito significativo para o PMDB e, para o PSDB, isto ocorre somente entre os não eleitos (na direção da concentração). Gastos de campanha afeta a todos os partidos e na mesma direção: mais gastos, votos mais dispersos. 


\section{Considerações finais}

Nesta análise procuramos verificar os efeitos de alguns elementos da base política dos partidos no padrão de votação dos candidatos. A ideia mestra que seguimos é que candidatos a cargos de nível nacional e seus partidos engendram apoios de nível local a fim de alcançar seus objetivos eleitorais. A presença da base local, sobretudo municipal, importa. Com uma série de distinções, que procuramos demonstrar, com efeitos diversos a depender do ator (partido) em jogo, mas ter base de apoio no nível local produz resultados eleitorais diferentes daqueles que não as tem. É claro que os gastos de campanha impactam muito mais, mas isto já sabíamos, por meio da vasta literatura existente. Os utilizamos para estabelecer uma medida de comparação com estes estudos. $\mathrm{O}$ achado mais relevante desta pesquisa está no município, onde vereadores e prefeitos “fazem campanha" para seu candidato e partido.

Das hipóteses lançadas, a primeira, que concerne ao comportamento dos partidos políticos, foi comprovada, embora não no sentido que esperávamos. De fato, os partidos apresentam distinções muito claras, mas isto não está diretamente relacionado à capilaridade de suas bases. PT e PMDB, que esperávamos ser semelhantes por terem similar grau de penetração no eleitorado, na maior parte dos indicadores se encontram em sentidos opostos. Os dados e a análise apresentados ajudam a reforçar que os partidos políticos são, sim, diferentes entre si - ao menos no que tange ao comportamento eleitoral. Ser um político profissional no PT é diferente de sê-lo no PMDB. A segunda hipótese, sobre os políticos profissionais, foi comprovada quando olhamos para o quadro geral, mas não teve os efeitos esperados na sua relação com as bases políticas entre o grupo dos eleitos. Estas bases políticas, contudo, no cenário geral, importam. Apresentamos correlações e um modelo de regressão de deixa o fenômeno claro.

Contudo, algumas das maiores diferenças estão entre os não eleitos. Isso poderia não significar absolutamente nada, mas em nosso sistema eleitoral isto significa. Os não eleitos são relevantes pois, no sistema eleitoral proporcional, os votos destes também contribuem para conseguir cadeiras na Câmara. Apenas a título de exemplo, $45,2 \%$ do total de 87 milhões, 846 mil e 543 votos dados a algum candidato a deputado federal em 2014 foram destinados a 
pleiteantes que totalizaram, individualmente, um irrisório máximo de 999 votos. Em 2014, 259 autodeclarados “vereadores" candidataram-se ao cargo de deputado federal. São estes, majoritariamente, os políticos profissionais não eleitos. Apesar de não eleitos, sua votação contribuiu para o partido atingir o quociente eleitoral. Para este grupo, aspectos da base política, como ter o governador do estado, fazem diferença. Ao fim das eleições, este grupo de não eleitos também produz impactos sobre os outcomes eleitorais. Isto nos indica, para futuras pesquisas, que para compreender as estratégias eleitorais dos partidos também precisamos olhar para como estes partidos mobilizam candidatos que, embora sem chances pessoais de vitória, contribuem para que a agremiação atinja o quociente eleitoral no atual modelo.

Este modelo de votação tem sido objeto de debate na sociedade há muitos anos. Com o tema da reforma política cada vez mais em voga, podemos pensar na primeira das três questões que o cientista político Harold Lasswell nos aconselha a responder em uma análise política (quem ganha o que, quando, como). A mudança do atual modelo eleitoral para um do tipo distrital tenderia, hipoteticamen$\mathrm{te}^{9}$, a prejudicar os partidos com voto mais disperso, ao passo que poderia beneficiar os com votos já mais concentrados. Os dados que apresentamos são relevantes pois podem responder quais partidos são estes.

Parte considerável da literatura tratada aqui aponta o movimento histórico de crescente desconcentração - ou dispersão - dos votos. Isso pode acontecer por diversos fatores, aos quais não temos acesso objetivo, como, a exemplo do argumento de Silva (2014), o aumento da concorrência eleitoral, que obrigaria os candidatos a expandirem sua base eleitoral original. A despeito de quais motivos ocasionam isto, a tendência é clara. Os dados apresentados nesta análise corroboram a tese, indicando a continuação desta tendência.

Demonstramos existir diferenças tanto partidárias quanto de ordem da base política, que afetam os padrões de comportamento dos candidatos. Em geral, estes adotam estratégias diferentes quando seus partidos estão fora ou no governo estadual - e esta é apenas uma das alterações provocadas por mudanças de cenário na base política. Se

9. Trata-se apenas de uma conjectura, não um determinante, pois os partidos são flexíveis e poderiam adaptar-se às novas regras. 
parcialmente, talvez, estes padrões possam ser atribuídos a questões regionais e estaduais, acreditamos que não ao todo. Diversas questões permanecem para serem respondidas futuramente, postas como uma agenda. Os efeitos apresentados aqui podem, potencialmente, ter ainda maior impacto sobre as eleições para deputado estadual. Em fato, o padrão de votação dos deputados estaduais é um tema que remanesce a ter aprofundado seu estudo. De forma ainda mais veemente, contudo, resta a ser pesquisado o papel de prefeitos e vereadores - o mais próximo vínculo do cidadão com a vida política - em todo este processo. No modelo de regressão (tabela 4), as variáveis mais significativas foram gastos de campanha (afinal, dinheiro importa) e ter vereadores em sua base de apoio. Diante de dezenas de estudos sobre o âmbito federal ou sobre a política estadual, o papel das bases locais na política brasileira tem sido esquecido, a despeito de sua importância para, ao menos, como se mostrou aqui, o jogo eleitoral.

\section{Referências bibliográficas}

AMES, Barry. (1995) Electoral Strategy under Open-List Proportional Representation. American Journal of Political Science, v. 39, n. 2, p. 406-433.

AVELINO, George; BIDERMAN, Ciro; BARONE, Leonardo. (2012) Articulações Intrapartidárias e Desempenho Eleitoral no Brasil. Dados, Rio de Janeiro, vol. 55, no 4, pp. 987 a 1013.

AVELINO, George; BIDERMAN, Ciro; SILVA, Glauco Peres da. (2011) A Concentração Eleitoral nas Eleições Paulistas: Medidas e Aplicações. Dados, vol. 54, n. 2, p. 319-347.

BRAGA, Maria do Socorro, PIMENTEL JR., Jairo. (2013) Estrutura e organização partidária municipal nas eleições de 2012. Cadernos Adenauer XIV, No2, 2013.

BRAGA, Sérgio \& NICOLÁS, Maria Alejandra (2008). Prosopografia a partir da web: avaliando e mensurando as fontes para o estudo das elites parlamentares brasileiras na internet. Rev. Sociol. Polít., Curitiba, v. 16, n. 30, p. 107-130.

BOLOGNESI, Bruno; CERVI, Emerson. (2011) Distribuição de recursos e sucesso eleitoral nas eleições 2006: Dinheiro e tempo de HGPE como financiadores de campanha a deputado federal do Paraná. IN: $35^{\circ}$ Encontro anual da ANPOCS, 24 a 28 de Outubro de 2011.

CARREY, J.; SHUGART, M. (1995) Incentives to cultivate a personal vote. Electoral Studies, v. 14, p. 417-439. 
CARVALHO, Nelson Rojas de; CORRÊA, Filipe Souza; GHIGGINO, Bianca. (2010) Entre o Localismo e Universalismo: a Geografia Social dos Votos e a Questão Metropolitana. In: 34 Encontro Anual da ANPOCS. Caxambú, 2010.

CARVALHO, Nelson Rojas de. (2009) Geografia política das eleições congressuais: a dinâmica de representação das áreas urbanas e metropolitanas no Brasil. Cadernos Metrópole, São Paulo, v. 11, n. 22, pp. 367-384, jul/dez 2009

CERVI, Emerson Urizzi. (2009) Produção legislativa e conexão eleitoral na assembléia legislativa do estado do Paraná. Rev. Sociol. Polit., Curitiba , v. 17, n. 32.

CODATO, Adriano; CERVI, Emerson; PERISSINOTTO, Renato (2013). Quem se elege prefeito no Brasil? 61 Condicionantes do sucesso eleitoral em 2012. Cadernos Adenauer. XIV. $\mathrm{N}^{\mathbf{2}} 2$.

COSTA, Luiz Domingos \& CODATO, Adriano. (2013) Profissionalização ou popularização da classe política brasileira? Um perfil dos Senadores da República. IN: MARENCO, André (org.). Os Eleitos: representação e carreiras políticas em democracias. Porto Alegre: Editora UFRGS.

COSTA, Luiz Domingos; CODATO, Adriano; MASSIMO, Lucas. (2013) Codificando profissões em estudos de elites políticas: uma discussão metodológica e tipológica. IN: Colóquio Elites em diferentes escalas: teoria e metodologia no estudo de grupos dirigentes. Curitiba, 12 e 13 setembro de 2013

COSTA, Luiz Domingos; BOLOGNESI, Bruno; CODATO, Adriano. (2015) Onde estão os trabalhadores nas listas de candidatos dos partidos brasileiros? In: Newsletter do observatório de elites políticas e sociais do brasil. v. 2, n.2.

CORADINI, Odaci Luiz. (2012) Categorias sócio-profissionais, titulação escolar e disputas eleitorais. Revista de Sociologia e Política, v. 20, n. 41, p. 109-122.

MARENCO DOS SANTOS, André (2001). Sedimentação de lealdades partidárias no Brasil: Tendências e descompassos. Revista Brasileira De Ciências Sociais Vol. $16 \mathrm{~N}$ o 45 .

MESQUITA, Lara; SILOTTO, Graziele; LUZ, Joyce; HUBERT, Paulo. (2014). Emendas individuais e concentração de votos: uma análise exploratória. Teoria \& Pesquisa, 23 (2)

PEREIRA, Carlos; RENNÓ, Lucio. (2001) O que É que o Reeleito Tem? Dinâmicas Político-Institucionais Locais e Nacionais nas Eleições de 1998 para a Câmara dos Deputados. Dados vol.44 no.2

RICCI, Paolo \& LEMOS, Leany Barreiro. (2004) Produção legislativa e preferências eleitorais na comissão de agricultura e política rural da câmara dos deputados. Revista Brasileira de Ciências Sociais, Vol. 19 nº 55

RODRIGUES, Leôncio Martins (2006). Mudanças na classe política brasileira. São Paulo: PubliFolha. 
(2002). Partidos, ideologia e composição social. Revista Brasileira de Ciências Sociais, v. 17, n. 48, p. 31-47.

ROJAS, Felipe Alejandro Guerrero \& CARLOMAGNO, Márcio Cunha. (2014). Elite política local e legislativo municipal no estado de São Paulo: partidos, ideologia e composição social. Agenda política, Vol. 2 - n. 1.

SILVA, Glauco Peres da. (2014) Para além de São Paulo: Medindo a Concentração Eleitoral em todo o Brasil. IN: IX Encontro da ABCP, 4 a 7 de agosto de 2014, Brasília.

SOARES, Gláucio Ary Dillon; TERRON, Sonia Luiza. (2008) Dois Lulas: a geografia eleitoral da reeleição (explorando conceitos, métodos e técnicas de análise geoespacial). Opinião Pública, Campinas, vol. 14, nº 2, p.269-301.

SPECK, Bruno. (2014) Recursos, partidos e eleições: o papel do financiamento privado, do Fundo Partidário e do horário gratuito na competição política no Brasil. IN: AVELAR, Lucia \& CINTRA, Antonio Otavio (org). Sistema Político Brasileiro: Uma Introdução.

SPECK, Bruno, MANCUSO, Wagner. (2013) O que faz a diferença? Gastos de campanha, capital político, sexo e contexto municipal nas eleições para prefeito em 2012. Cadernos Adenauer XIV, $n^{\circ} 2$

TERRON, Sonia Luiza; SOARES, Gláucio Ary Dillon. (2010) As bases eleitorais de Lula e do PT: do distanciamento ao divórcio. Opinião Pública, Campinas, vol. $16, n^{\circ} 2$, p.310-337

ZUCCO JR., Cesar. (2009) Esquerda, Direita e Governo: A ideologia dos partidos políticos brasileiros. In: Seminário Legislator Views of Brazilian Governance. Universidade de Oxford. 
